\title{
IMPORTÂNCIA DE AULAS PRÁTICAS E TECNOLOGIAS PARA AULAS DE QUÍMICA
}

\author{
Soleika Gorete Lunkes ${ }^{1}$ \\ Maria Fatima Menegazzo Nicodem² \\ José Gilmar Kurtz ${ }^{3}$ \\ Paulo Sérgio Mohr ${ }^{4}$
}

RESUMO: O objetivo deste trabalho foi evidenciar a importância das aulas experimentais e uso da tecnologia no ensino e estudo de Química. Tratou-se de uma pesquisa de campo com a utilização de questionários dotados de 12 questões, aplicados a 30 alunos de um colégio estadual no município de Itaipulândia, PR. Os resultados demonstraram que apenas 3,33\% gostam sempre de química e 50\% deles acham a disciplina de difícil compreensão. Dentre os entrevistados 50\% gosta das aulas práticas e $63,3 \%$ citam que a experimentação ajuda sempre na compreensão da disciplina. Da mesma forma que $40 \%$ afirmam que a tecnologia ajuda a melhorar o ensino da Química. Porém, 80\% acreditam que as aulas práticas precisam ser melhoradas e $36,67 \%$ confirmam que a interligação entre a teoria e o cotidiano dos alunos facilita o entendimento da matéria. Desta forma, os resultados obtidos demonstram que o desinteresse dos alunos pelo estudo da química se deve, em geral, a ausência de tecnologias ou a necessidade de melhorias nas aulas práticas. Pode-se constatar também, a falta de inter-relação entre o que é ensinado em sala de aula e o cotidiano do aluno. Por esse motivo, muitos alunos não percebem a importância e a contribuição da química para suas vidas.

Palavras-chaves: Ensino de Química. Aulas práticas. Tecnologias.

ABSTRACT: The aim of this study was to demonstrate the importance of experimental classes and use of technology in teaching and Chemistry study. This was a field research using questionnaires provided with 12 questions applied to 30 students of a state school in the city of Itaipulândia, PR. The results showed that only $3.33 \%$ always like chemistry and $50 \%$ of them think the discipline difficult to understand. Among respondents $50 \%$ like the practical classes and $63.3 \%$ cite that experimentation always helps in understanding the

\footnotetext{
${ }^{1}$ Graduada em Tecnologia em Gestão Ambiental pela Universidade Tecnológica Federal do Paraná-UTFPR (20II). Especialista em Educação Especial, Psicomotricidade, Educação do Campo e Gestão Escolar. Possui Licenciatura em Química, Ciências Biológicas e Pedagogia.-E-mail: soleikalunkes@gmail.com.

${ }^{2}$ Doutora em Educação/ UEM, Pós Doc em Educação do Campo/ UEM. Professora UTFPR- Universidade Tecnológica Federal do Paraná. -E-mail: fatimanicodem@hotmail.com.

${ }^{3}$ Graduado em Educação Física pela Uniguaçu Faesi (2008). Licenciado em Filosofia pela Unipar Universidade Paranaense (2018). Especialista em Metodologia do Ensino de Filosofia e Sociologia e Educação do Campo pela Faculdade São Luís (2020). E-mail: gilmarkurtz8o@gmail.com.

${ }^{4}$ Graduado em Educação Física pela Unipar - Universidade Paranaense (2004). Especialista em Metodologias Inovadoras Aplicadas à Educação e Educação Especial Inclusiva pela Faculdade Internacional de Curitiba Facinter (2008). Associado ao CREF - PR como treinador esportivo. Atuação na rede Estadual e Privada de ensino. E-mail: paulo.mohr@bol.com.br.
} 
discipline. Just as $40 \%$ say that technology helps improve the teaching of chemistry. However, $80 \%$ believe that the practical classes need improvement and $36.67 \%$ confirm that the connection between the theory and the daily lives of students facilitates the understanding of matter. Thus, the results demonstrate that the lack of interest of students for chemistry study should, in general, the lack of technology or the need for improvement in practical classes. It can be seen also, the lack of interrelation between what is taught in the classroom and the daily life of the student. For this reason, many students do not realize the importance and the chemical contribution to their lives.

Key-words: Chemistry teaching. Practical classes. Technologies.

\section{INTRODUÇÃO}

A Química caracteriza-se como uma ciência experimental de grande importância para as demais ciências, visto que está presente em tudo que nos rodeia. Tem por objetivo o estudo da matéria desde sua composição, estrutura e propriedades, além de suas transformações.

Entretanto, o ensino da Química e de outras ciências, tem sido realizado da forma tradicional, e na maioria das vezes tem se tornado exaustivo para os alunos. Isso ocorre, pois não há didática adequada e não há participação efetiva dos alunos.

Outros fatores estão vinculados com a dificuldade no aprendizado da Química, dentre eles, destaca-se a ausência de interligação com a realidade do aluno, falta de aulas experimentais relacionadas com a teoria estudada em sala de aula, despreparo dos professores e ausência de tecnologia para o ensino da disciplina.

Neste sentido, a realização de aulas práticas seria um facilitador na aprendizagem da Química. Além do mais, a conexão entre o que ensinado na escola com o cotidiano do aluno tornaria o ensino mais interessante e proveitoso. Ademais, a teoria e a prática dependem uma da outra, sendo que na teoria é explicado a matérias sem o manuseio de substâncias e a prática está ligada ao manejo de substâncias e a visualização de reações químicas.

Ainda por cima, é preciso aproveitar a tecnologia e modernizar o ensino da Química, como a utilização de apresentações dinâmicas e jogos didáticos digitais, por exemplo, que são capazes de facilitar e agilizar a aprendizagem. A inserção da tecnologia como ferramenta didática aumenta a motivação dos alunos e a eficiência do aprendizado.

Desta forma, perante a necessidade de um ensino da Química inovador, através de aulas práticas e uso de recursos tecnológicos, o presente trabalho teve por objetivo 
investigar a importância de aulas experimentais e tecnológicas como ferramenta de aprendizado no ensino de Química.

\section{FUNDAMENTAÇÃO TEÓRICA}

\section{I Ensino da Química}

A Química é por definição uma ciência que estuda a matéria, suas transformações químicas e as variações de energia que acompanham estas transformações. E desta forma, representa um fator importante em todas as ciências naturais, básicas e aplicadas (BUENO et al., 2003).

Tem por objetivo principal a formação de cidadãos conscientes e críticos (TREVISAN E MARTINS, 2006), e para Chassot (1990) isso se deve ao fato de que "a Química é também uma linguagem. Assim, o ensino da Química deve ser um facilitador da leitura do mundo. Ensina-se Química, então, para permitir que o cidadão possa interagir melhor com o mundo".

Entretanto, o ensino de Química nas escolas está baseado na fala do professor e na repetição do que foi dito (MACÊDO et al., 2010), seja na memorização de informações, nomes, fórmulas e conhecimentos, sem interligação com a realidade do aluno (ARAÚJO, 2014; PAZ et al., 2010). Ao contrário disso, os Parâmetros Curriculares Nacionais para o Ensino Médio (PCNEM) (BRASIL, 2002) enfatizam que os conteúdos devem apresentar relação com o cotidiano do aluno, seus interesses e vivências.

Além disso, é preciso apresentar ao aluno um conceito de ciência como atividade humana em construção, ou seja, aderir a metodologias, como a experimentação, que contribuam para a melhor aprendizagem da Química (OLIVEIRA E SILVA, 2012). De acordo com Moréia et al. (2009), a atividade prática se baseia na "transformação e observação das substâncias nos laboratórios e nas indústrias, quando se trabalha em nível macroscópico, isto é, ao se abordar manifestações palpáveis, visíveis ou detectáveis por equipamentos específicos".

Não obstante, a utilização de tecnologia no processo educacional torna o conhecimento em Química uma atividade mais atrativa, visto que favorece uma visão holística da apresentada pelos livros didáticos e da discussão interclasse (SANTOS, 20II). 
Essa tecnologia não se limita apenas a computadores, mas a todos os novos recursos e equipamentos criados para melhorar o aprendizado e a vida social (ESPANHOL, 2014).

\subsection{Dificuldades de aprendizagem em Química}

Além dos problemas já citados Da Silva (20II), cita que o ensino da Química está em declínio em virtude de vários fatores, são eles: a) deficiência na formação do professor; b) baixos salários dos professores; c) metodologia em sala de aula ultrapassada; d) redução na formação de licenciados em química; e) poucas aulas experimentais; f) desinteresse alunos. Inclusive, em alguns programas escolares uma quantidade enorme de conteúdos precisa ser repassada aos alunos o que acaba acumulando muitos assuntos na cabeça dos estudantes (PAZ et al., 2010).

Para Bueno et al. (2003) a ausência de correlação entre aulas teóricas e práticas é a maior dificuldade encontrada no ensino da Química. Entretanto, alguns professores, apesar de compreenderam a importância de aulas experimentais, argumentam as dificuldades para que isso aconteça. Dentre eles, destaca-se: número reduzido de aulas de Química, falta de material para orientação, ausência de laboratório, falta de formação docente, escassez de bibliografia específica e atualizada, falta de tempo para o preparo das atividades e de professores para auxiliarem as atividades (GARCIA BARROS, 1995).

Em vista disso, cabe ao professor buscar alternativas para superar essas dificuldades que intervém no aprendizado dos alunos, pois é "por causa deles que os alunos passam a conhecer ou ignorar a Química" (TORRICELLI, 2007). Silva et al. (2010) enfatiza que o laboratório pode ser qualquer ambiente que os alunos estejam inseridos diariamente e não, necessariamente, um laboratório tradicional. Ou mesmo, utilizar materiais alternativos de fácil manipulação, baixo custo e que possam ser encontrados no dia a dia dos alunos (DIAS et al., 2013).

\subsection{Importância das aulas práticas no ensino da Química}

De acordo com Plicas et al. (2010), “o ensino teórico, não favorece nem permite uma aprendizagem completa”. A ausência de conexão entre a teoria e a prática interfere na relevância dos conteúdos e, consequentemente, na formação do indivíduo (BUENO et al., 2013). 


\begin{abstract}
A experimentação não deve ser passada de forma desvinculada da teoria, mais sim de forma complementar, pois a prática sem o embasamento teórico não teria um caráter propriamente científico, e a teoria sem a prática muitas vezes não permite que o aluno tenha uma assimilação efetiva. (LINS et al. s/d).
\end{abstract}

Assim, a aula experimental pode contribuir para a melhoria na aprendizagem de Química (ARAÚJO, 2014), visto que pode auxiliar o aluno na compreensão de fenômenos e conceitos químicos (MARCONDES, 2008). Ainda por cima, "deve ser aproveitado como agente facilitador da interação professor-aluno embora represente dificuldades de ordem material que tornam a experimentação proibitiva em escolas com poucos recursos" (TORETTI et al., 2003).

Para Krasilchik (2004), nas aulas práticas os alunos confrontam-se com resultados não previstos, e a interpretação destes desafia sua imaginação e raciocínio. Além de permitir que os alunos entrem em contato com diversas etapas, como a manipulação observação, investigação e interpretação (MACÊDO et al., 2010).

Além do mais as aulas práticas instigam a curiosidade, a iniciativa e a autoconfiança; melhoram o desenvolvimento de habilidades linguísticas, mentais e de concentração; e exercitam interações sociais e trabalho em equipe (VYGOTSKY, 1989).

\title{
2.4 Tecnologias e ensino da Química
}

Seja ao longo da vida, na escola ou no ambiente familiar, os conhecimentos tecnológicos já fazem parte do cotidiano de muitos jovens que frequentam o ensino secundário (COSTA E OLIVEIRA, 2012).

Nos últimos anos, é notável o grande desenvolvimento de tecnologias de informações, e esse avanço tem transformado o computador em uma importante ferramenta para a educação por fornecer um novo e interativo meio de superar a falta de tempo e o distanciamento entre os estudantes (MATHIAS et al, 2009).

"A tecnologia pode imprimir um rumo diferente à sala de aula" (FURTADO, 20I6), pois é um instrumento de inclusão social, auxilia no processo ensino-aprendizagem, além de ser fundamental para a construção do saber e suporte para as aulas. Ainda mais, estimula a busca de informações e promove a interação e cooperação entre os alunos e professores (FURTADO, 2016). 
Escartin (2000) acrescenta que a utilização do computador favorece o estudo e modelagem de processos e fenômenos de dimensão espacial, e enfatiza que não existem limitações de idade na aplicação da tecnologia na educação, podendo beneficiar-se alunos desde a primária até ao universitário.

[...] uma das formas de se promover um ensino de qualidade é através do emprego de tecnologias que se apresentem como uma ferramenta pedagógica que propicie a integração do aluno no mundo digital, através da otimização dos recursos disponíveis, possibilitando uma multiplicidade de formas de acesso ao conhecimento, de forma dinâmica, autônoma, prazerosa e atual” (LIMA E MOITA, 2011, p. 134).

Costa e Oliveira (2012) concluem que o avanço das tecnologias de informação e comunicação permitiram novos métodos de difusão do conhecimento e que se forem utilizadas de forma inovadora, podem abrir novos horizontes na aprendizagem das ciências e da matemática.

\section{PROCEDIMENTOS METODOLÓGICOS DA PESQUISA}

\section{I Local da Pesquisa}

O município de Itaipulândia está localizado na região oeste do Paraná, conforme a Figura I. Emancipou-se em 1992 e de acordo com o censo do IBGE 2015, conta com 10.236 habitantes e área territorial de $331,288 \mathrm{~km}^{2}$.

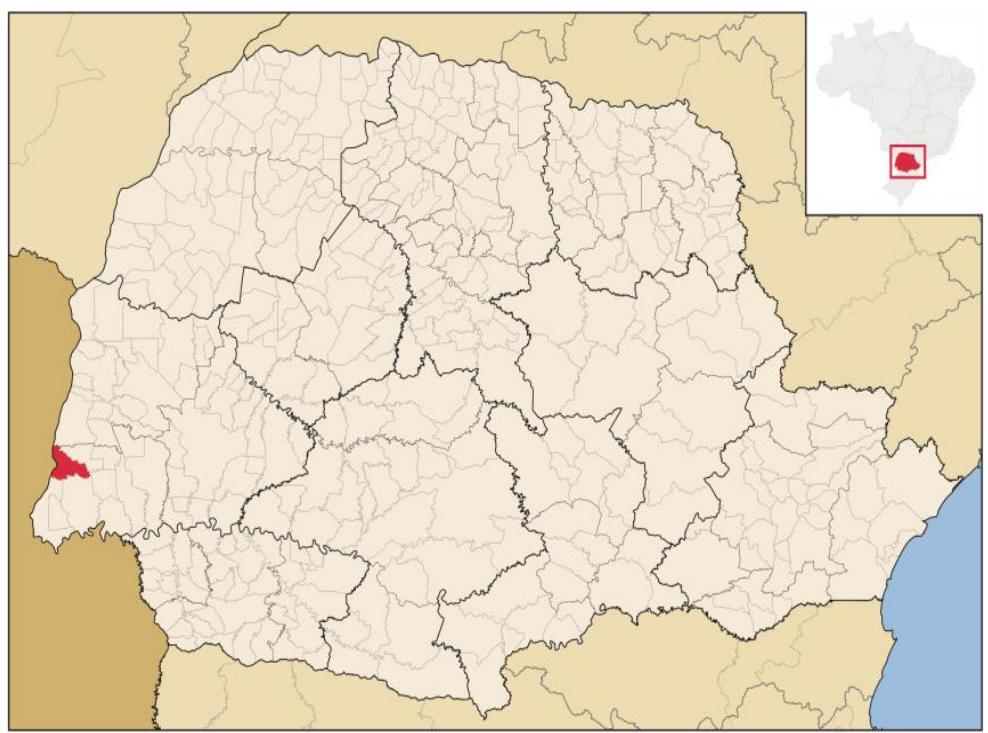

Figura I: Localização geográfica do município de Itaipulândia, PR. 
Fonte: Prefeitura Municipal de Itaipulândia, 202I.

\subsection{Tipo de Pesquisa}

Trata-se de uma pesquisa exploratória e em relação aos procedimentos técnicos classifica-se em levantamento ou pesquisa de campo. Para a realização desta pesquisa utilizou-se a técnica de aplicação de questionário (APÊNDICE A). A pesquisa buscou obter informações sobre a visão dos alunos diante da utilização da experimentação e tecnologias no ensino de Química.

\subsection{População e Amostra}

A pesquisa foi realizada com 30 alunos, de idade entre 16 a 20 anos, do $2^{\circ}$ ano do Colégio Estadual Costa e Silva, sendo I8 do sexo feminino e I2 do sexo masculino.

\subsection{Análise dos Dados}

A análise dos dados deu-se por estimativas percentuais, de acordo com as respostas dadas pelos alunos.

\section{RESULTADOS E DISCUSSÕES}

De acordo com a Figura 2, pouco mais de 3\% dos alunos entrevistados gostam sempre de Química, demonstrando ser uma disciplina de difícil compreensão pelos alunos (VIEIRA et al., 20II). Porém, por ser uma ciência experimental as atividades práticas tem auxiliado para o melhor aprendizado dos estudantes. Isto pode ser observado na Figura 3, em que mais da metade dos alunos concordam que as aulas experimentais têm contribuído muito para facilitar o entendimento do conteúdo da disciplina.

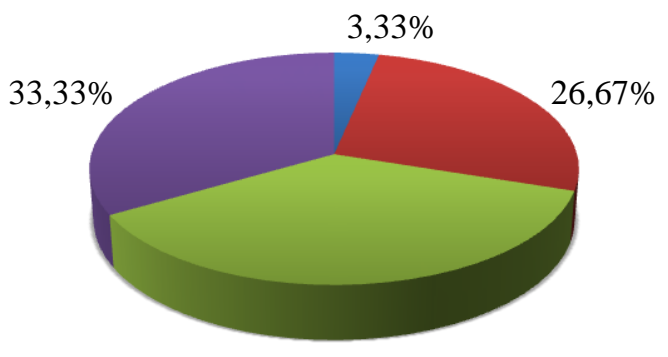

$36,67 \%$
- Sim, Sempre

- Sim, dependendo do conteúdo

às vezes

Não gosto nunca 
Figura 2: Questão para saber se o aluno gosta ou não da disciplina de Química.

Entretanto, boa parte acredita que nem todo conteúdo é facilitado com as aulas práticas e por vezes, nem as atividades práticas ajudam. Isso pode ser justificado pelo fato de que muitas vezes a experimentação não alcança os objetivos esperados, pois são apresentadas sem uma problematização, apenas justificando uma teoria apresentada em sala de aula (PLICAS et al., 2010).

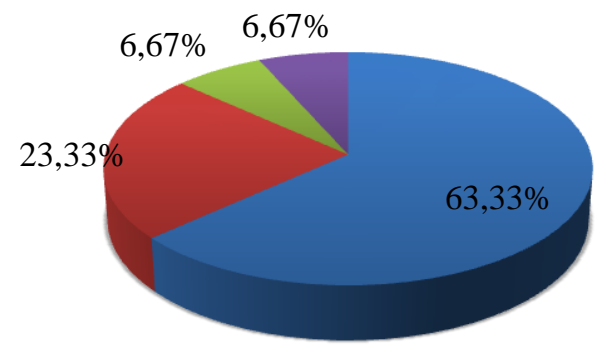

- Sim, Sempre

- Sim, dependendo do conteúdo

Às vezes

- Não ajuda muito

Figura 3: As aulas práticas contribuem no entendimento da disciplina de Química.

Apesar de uma pequena porcentagem gostar de Química, nenhum dos entrevistados cita a matéria como de fácil compreensão (Figura 4). Pelo contrário, metade deles acha difícil. Desta forma, para que as aulas tornem-se mais atraentes e produtivas, a experimentação deve envolver temas e problemas relacionados com o dia a dia dos alunos, visto que a ausência disso dificulta o processo de ensino-aprendizagem e a compreensão dos conteúdos (LIMA et al., 2000).

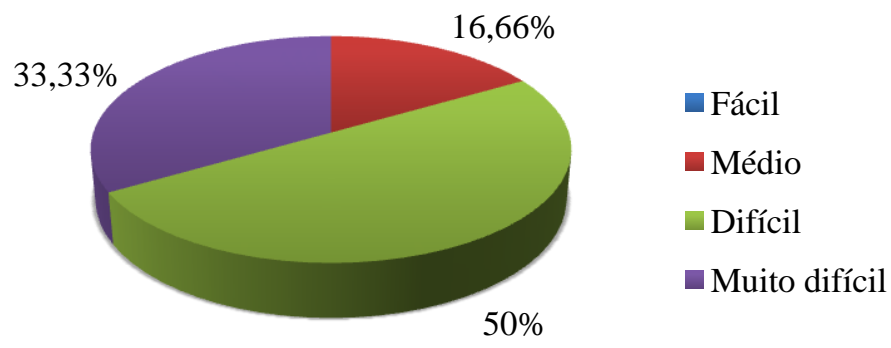


Figura 4: Nível de compreensão da disciplina de Química.

De acordo com a Figura 5, mais da metade considera a disciplina de Química importante e $20 \%$ a consideram muito importante para seu dia a dia. Resultado parecido foi constatado por Silva e Silva (2008), em que 42\% dos roo alunos entrevistados consideraram a Química importante, pois através dela terão a possibilidade de conhecer substâncias e fenômenos da natureza.

Entretanto, mesmo com toda sua importância, muitos alunos tem dificuldade em assimilar conceitos básicos de Química, por isso acreditam que a disciplina não serve pra nada.

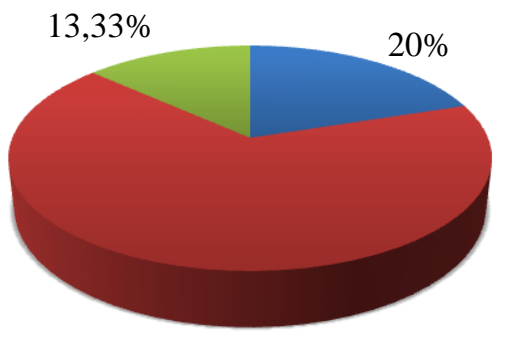

- Muito importante

- Médio

Não serve pra nada

$66,66 \%$

Figura 5: Grau de importância da disciplina de Química.

Metade dos estudantes entrevistados gosta das aulas práticas (Figura 6), enfatizando sua importância para melhor ensino-aprendizado da matéria. Além disso, a experimentação contribui para despertar o interesse pela disciplina, pois "facilita a compreensão da natureza da ciência e dos seus conceitos, auxilia no desenvolvimento de atitudes científicas e no diagnóstico de concepções não-científicas” (MACÊDO et al., 2010). 


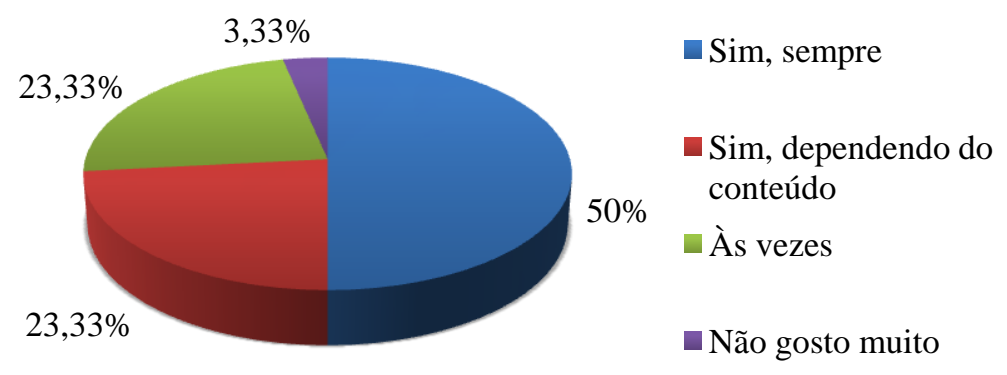

Figura 6: Gosta de aulas práticas.

Em função de grande parte dos alunos não gostar da disciplina e achar difícil, 80\% deles esperam melhorias nas aulas de Química, conforme a Figura 7.

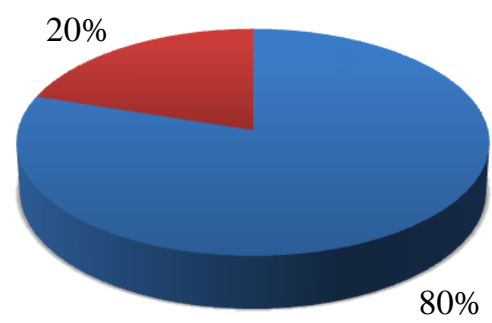

- Sim, muita coisa

- Não, não é necessário melhorar, porque as aulas são ótimas

Figura 7: Necessidade de melhoria nas aulas de Química.

$\mathrm{Na}$ questão 7, Figura 8, parte dos alunos acredita que exemplos do cotidiano facilitam o aprendizado e parte cita que somente às vezes ajuda. Em estudo realizado por Araújo (2014), 95\% dos alunos acredita que a experimentação minimiza as dificuldades encontradas na disciplina de Química e que para melhor compreensão do conteúdo é necessário que seja ultrapassado os limites da sala de aula para o cotidiano do aluno. 


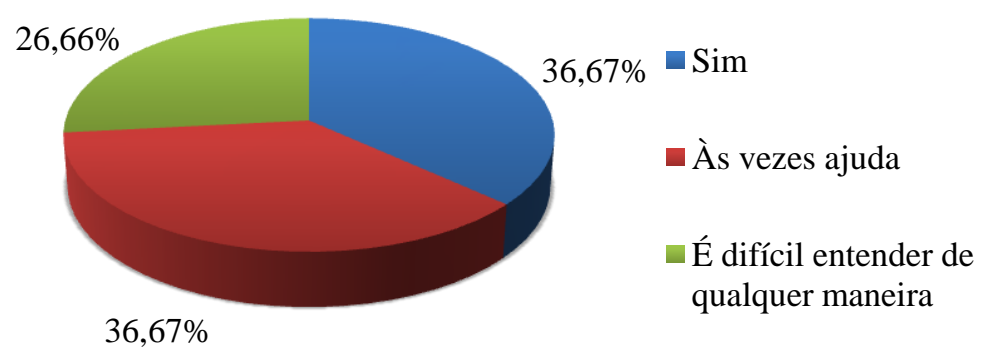

Figura 8: Exemplos do cotidiano facilitam o aprendizado.

Quanto a questão 8, Figura 9, mais da metade dos alunos acredita que a Química é, algumas vezes, responsável pela poluição no planeta, e apenas 10\% citam que jamais esta é a responsável por isso.

Uma forma de ensinar os alunos sobre a real participação da Química na poluição do planeta seria a aplicação de um jogo direcionado ao tema, como poluição atmosférica e impactos ambientais. Desta forma, ao final, o aluno compreenderia como se constituiu esses fenômenos e as substâncias que estão interligadas a isso. Ainda, entenderia melhor a obtenção do conhecimento da Química, a mudança da vida dos seres vivos, devido aos impactos e sua contribuição para o desenvolvimento sustentável (LIMA E MOITA, 20II).

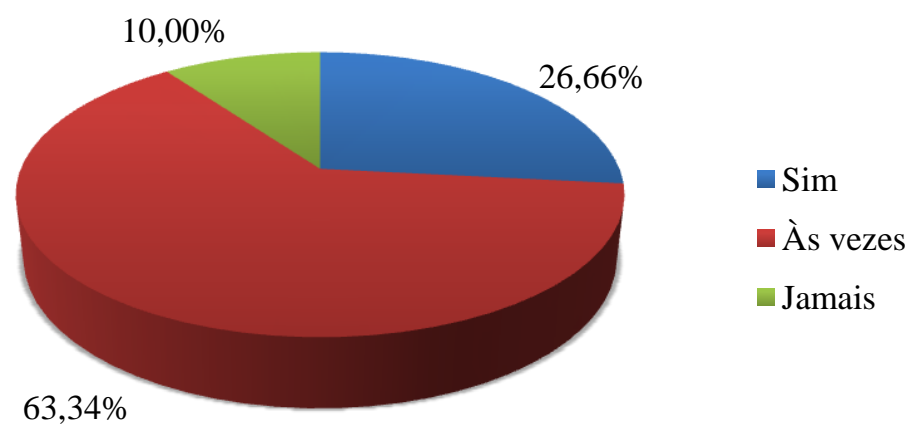

Figura 9: A Química é responsável por toda poluição existente no planeta.

A Figura io corresponde a questão 9, quanto a importância das descobertas realizadas pela Química para a vida do aluno. Dos 30 alunos, 23,33\% acreditam que essas descobertas não influenciam em nada em sua vida. Apesar de ser um valor baixo perto dos que citam que sim e às vezes influencia, é um valor considerável, visto que estes alunos 
ainda não tiveram a percepção de que a Química, na verdade, está em tudo o que nos rodeia. Este fato enfatiza ainda mais a necessidade de se interligar os temas estudados em sala com o cotidiano do aluno.

Da mesma forma, para a questão ı, que 16,66\% dos entrevistados acreditam que a Química jamais contribui para a sua vida.

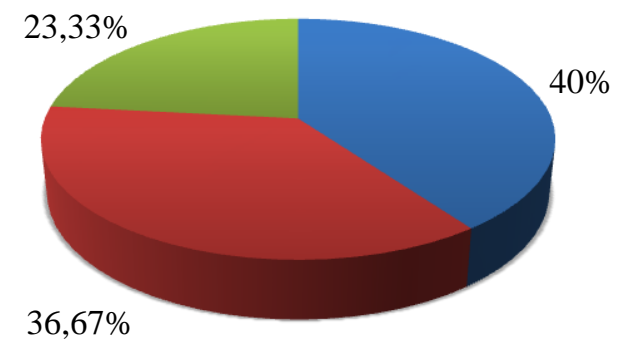

$$
\begin{aligned}
& \text { Sim } \\
& \text { Às vezes } \\
& \text { Não influencia em } \\
& \text { minha vida }
\end{aligned}
$$

Figura ro: Descobertas realizadas pela Química são importantes para a vida do aluno.

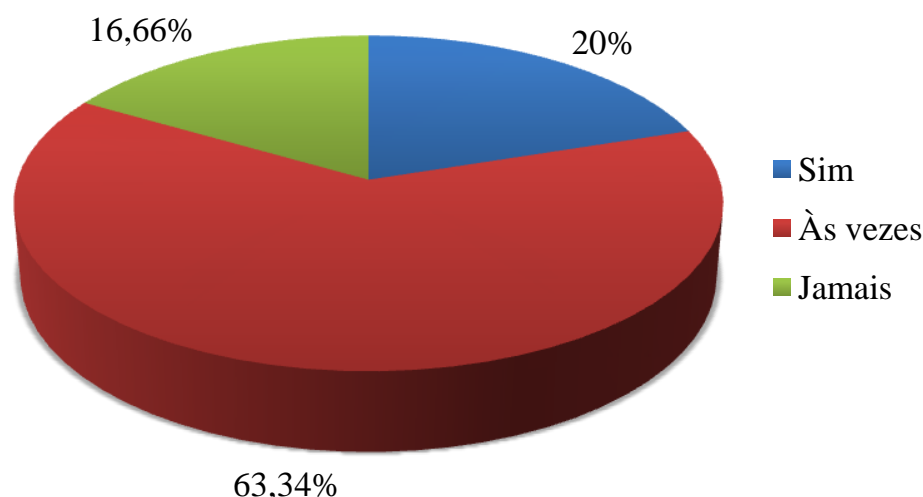

Figura II: $\mathrm{O}$ que é ensinado em Química contribui para sua vida?

A questão 12 refere-se ao uso das tecnologias, se contribui ou não para o ensino da Química. 40\% dizem que sempre e outros 40\% que depende do conteúdo trabalhado. Se a implantação da tecnologia no ensino da Química for planejada, "pode propiciar um conjunto de práticas preestabelecidas que têm o propósito de contribuir para que os alunos se apropriem de conteúdos sociais e culturais de maneira crítica e construtiva" (LIMA E MOITA, 20II). 
Além disso, os autores enfatizam que uma das formas de se promover um ensino de qualidade é a implantação de tecnologias que propiciem a integração do aluno no mundo digital, com a otimização dos recursos disponíveis, e que possibilite diversas formas de acesso ao conhecimento, de forma dinâmica, autônoma, prazerosa e atual.

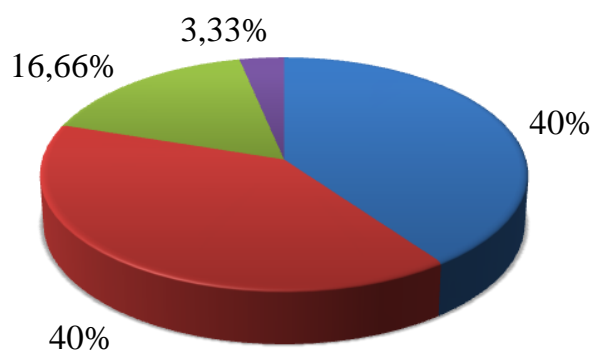

$\square$ Sim, sempre

$\square$ Sim, dependendo do conteúdo

$\square$ Às vezes

Ⓝão, nunca

Figura 12: $\mathrm{O}$ uso de tecnologias contribui para melhor compreensão da disciplina de Química.

A Figura 13 justifica todos os demais dados apresentados, visto que maior parte dos professores não utiliza nenhuma tecnologia para o ensinamento da Química. Esse fato demonstra a dificuldade e desinteresse dos alunos quanto à disciplina.

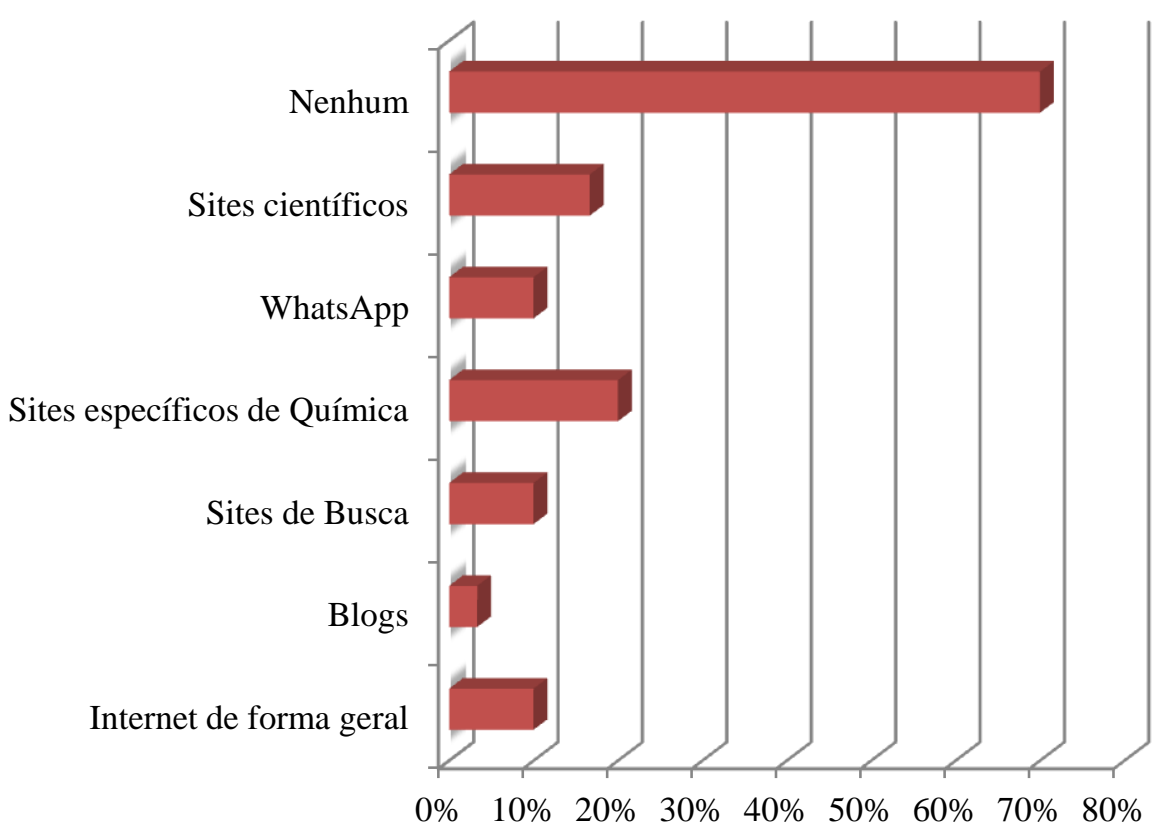

Figura 13: Tecnologias utilizadas pelos professores em sala de aula. 
Kenski (2004) enfatiza que são exigidas outras maneiras de pensar e fazer educação. As novas tecnologias condicionam a reorganização dos currículos, das formas de gestão e das metodologias utilizadas na prática educacional.

Da mesma forma, que as aulas práticas conduzem, quando bem orientadas, a uma formação de conceitos e estabelecimento de princípios, desenvolvendo o pensamento teórico-abstrato do aluno, levando-o a um preparo verdadeiro (MORTIMER, 200o).

\section{CONSIDERAÇÕES FINAIS}

Os resultados obtidos demonstram um grande desinteresse dos alunos pelo estudo da Química. Isso acontece, pois muitos acham a disciplina difícil ou muito difícil e sentem necessidade de melhoria nas aulas de Química.

Outros fatores que estão interligados a esse desinteresse se deve, em geral, a ausência de tecnologias ou a necessidade de melhorias nas aulas práticas, sendo que $80 \%$ dos alunos destacam essa necessidade. Pode-se constatar também, a falta de inter-relação entre o que é ensinado em sala de aula e o cotidiano do aluno. Por esse motivo, muitos alunos não percebem a importância e a contribuição da Química para suas vidas, como é o caso dos 63,34\% que acreditam que a Química é responsável por parte da poluição no mundo.

Portanto, a experimentação e a utilização da tecnologia podem facilitar o processo de ensino-aprendizagem da Química. Além disso, é necessário interligar os conteúdos da disciplina e temas do cotidiano dos estudantes, pois esses exemplos servirão de suporte para a compreensão do tema estudado.

\section{REFERÊNCIAS}

ARAÚJO, Antônia M. L. O ensino de química por meio de atividades experimentais: em busca de melhorias do conteúdo de mistura e substâncias na escola Landri Sales na cidade de Picos. In: III EITEC. Piauí. Anais eletrônicos... Piauí, 2014. Disponível em : < http://eitecpicos.com/novo/files/EITEC-

III/O\%2oensino\%2ode\%2oqu\%C3\%ADmica\%2opor\%2omeio\%2ode\%2oatividades\%2oexpe rimentais\%20em\%2obusca\%20de\%2omelhorias\%2odo\%2oconte\% $\mathrm{C}_{3} \%$ BAdo\%2ode\%2omist ura\%20e\%2osubstancias\%20na\%20escola\%2oLandri\%20Sales\%20na\%2ocidade\%20de\%20Pic os.pdf > Acesso em: 24 jun. 2016. 
BRASIL. As Novas Diretrizes Curriculares que Mudam o Ensino Médio Brasileiro. Brasília, DF: Ministério da Educação, 2002.

BUENO, Ligia et al. O ensino de química por meio de atividades experimentais: a realidade do ensino nas escolas. São Paulo, 2003. Disponível em: <http://unesp.br/prograd/ENNEP/Trabalhos\%2oem\%2opdf\%20\%20Encontro\%2ode\%2oEnsino/T4.pdf $>$. Acesso em: I6 jun 2016.

CHASSOT, A. A Educação no Ensino de Química. Ijuí: Unijuí, 1990.

COSTA, Henriqueta; OLIVEIRA, Isolina. O uso das tecnologias no ensino das ciências: resultados preliminares de um estudo no âmbito de cursos de natureza profissionalizante. In: II CONGRESSO INTERNACIONAL TIC E EDUCAÇÃO. Lisboa, Portugal. Anais eletrônicos... Lisboa, 2012. Disponível em: 〈http://ticeduca.ie.ul.pt/atas/pdf/atas.pdf〉 Acesso em 21 jun. 2016.

PAZ, G. L; NETO; C. O.C.; OLIVEIRA, M. L. Dificuldades no ensino-aprendizagem de química no ensino médio em algumas escolas públicas da região sudeste de Teresina. In: $8^{\circ}$ SIMPÓSIO BRASILEIRO DE EDUCAÇÃO QUÍMICA. Natal, RN. Anais eletrônicos... $\quad$ 2oro. Natal, Disponível em: http://www.abq.org.br/simpequi/2010/trabalhos/196-4222.htm> Acesso em: 20 jun. 2016.

DA SILVA, Airton M. Proposta para tornar o ensino de química mais atraente. Revista de

Química Industrial, n. 731, 2011.

DIAS, J. H. R. et al. A utilização de materiais alternativos no ensino de Química: um estudo de caso na E. E. E. M. Liberdade do município de Marabá - Pará. In: SOCIEDADE BRASILEIRA DE QUÍMICA (SBQ). Águas de Lindóia - SP. Anais eletrônicos... Águas de Lindóia, 2013.

ESCARTIN, E. R. La realidade virtual, una tecnologia educativa a nuestro alcance. Revista Píxel, n. 15, 2000.

ESPANHOL, Evandro. O uso da internet para promoção da transdisciplinaridade no ensino de química. 2014. $57 \mathrm{f}$. Monografia (Especialização em Ensino de Ciências) Departamento de Educação a Distância, Universidade Tecnológica Federal do Paraná, Medianeira, 20I4.

FURTADO, Hamilton $\mathrm{H}$. Tecnologia nas aulas de matemática, física e química. 2016. Disponível em: < http://www.artigonal.com/educacao-artigos/tecnologia-nas-aulas-dematematica-fisica-e-quimica-7372299.html

$>$ Acesso em 26 jun. 2016.

GARCIA BARROS, S; MARTINEZ LOSADA, M.C.; MONDELO ALONSO,M. El Trabajo Práctico, Una Intervencion para La Formacion de Professores. Enseñanza de Las Ciências,v. 13, n. 2, p.203-209, 1995. 
Instituto Brasileiro de Geografia e Estatística. 2015. Itaipulândia, PR. Disponível em: 〈http://www.cidades.ibge.gov.br/xtras/perfil.php?lang=\& codmun=4II095\&search $=\|$ infog r\%EIficos:-informa\%E7\%F5es-completas> Acesso em: 21 jun. 2016.

KENSKI, V. M.. Tecnologias e ensino presencial e a distância. 2. ed. Campinas: Papirus, 2004 .

Krasilchik, M. Prática de Ensino de Biologia. 4. ed. São Paulo: Universidade de São Paulo, 2004 .

LIMA, Érika R. P. O. L.; MOITA, Filomena M. G. S. C. A tecnologia e o ensino de química: jogos digitais como interface metodológica. In: SOUSA, R. P. MIOTA, F. M. C. S. C.; CARVAlHO, A. B. G. Tecnologias digitais na educação [online]. Campina Grande: EDUEPB, 2011, 276 p.

LIMA, Jozária de Fátima L.; PINA, Maria do Socorro L.; BARBOSA, Rejane M. N.; JÓFILI, Zélia M. S.; A contextualização no ensino de cinética química. Química Nova na Escola, n. II, 2000.

LINS, E. A. S. et al. Aula experimental no contexto do ensino da química: Uma busca para construção do conhecimento científico no ensino médio [s/d]. Disponível em: < http://annq.org/eventos/upload/1330462223.pdf>. Acesso em: i9 jun. 2016.

MACÊDO, Gláucia M. E. et al. A utilização do laboratório no ensino de química: facilitador do ensino-aprendizagem na escola estadual professor Edgar Tito em Teresina, Piauí. In: V CONNEPI, Maceió. Anais eletrônicos... Maceió, 2010. Disponível em: 〈http://connepi.ifal.edu.br/ocs/index.php/connepi/CONNEPI2oro/paper/view/r430〉 Acesso em: 27 jun. 2016.

MARCONDES, Maria E. R. Proposições metodológicas para o ensino de química: oficinas temáticas para a aprendizagem da ciência e o desenvolvimento da cidadania. Em Extensão, Uberlândia, v. 7, 2008.

MATHIAS, Gisele N.; BISPO, Márcia L. P.; AMARAL, Carmen L. C. Uso de tecnologias de informação e comunicação no ensino de química no ensino médio. In: VII ENCONTRO NACIONAL DE PESQUISA EM EDUCAÇÃO EM CIÊNCIAS. Florianópolis, Santa Catarina. Anais eletrônicos... Florianópolis, 2009. Disponível em: 〈http://posgrad.fae.ufmg.br/posgrad/viienpec/pdfs/II77.pdf〉 Acesso em: 21 jun. 2016.

MORÉIA, K. C. et al. O desenvolvimento de aulas práticas de química por meio da montagem de kits experimentais. In: $2^{-}$ENCONTRO DO NÚCLEO DE ENSINO DA UNESP DE PRESIDENTE PRUDENTE. Presidente Prudente, São Paulo. Anais eletrônicos... Presidente Prudente, 2007. Disponível em 〈http://www.unesp.br/prograd/ENNEP/Trabalhos\%2oem\%2opdf\%20\%2oEncontro\%2ode\%2oEnsino/T3.pdf> Acesso em: 21 jun. 2016. 
MORTIMER, E. F. Linguagem e Formação de Conceitos no Ensino de Ciências.ı ed. Belo Horizonte: Editora UFMG, 2000.

OLIVEIRA, C. A. L.; SILVA, T. P. Aplicação de aulas experimentais de Química com materiais alternativos a partir de sucata e materiais domésticos no ensino de jovens e adultos (EJA). In: ENCONTRO NACIONAL DE EDUCAÇÃO CIÊNCIA E TECNOLOGIA DA UEPB. Paraíba. Anais eletrônicos..., v.I, n. I, 2012. Disponível em: $\langle$ http://www.editorarealize.com.br/revistas/enect/resumo.php?idtrabalho=93〉 Acesso em: 22 jun. 2016.

PLICAS, Lidia M. A.; PASTRE, Iêda A.; TIERA, Vera A. O. O uso de práticas experimentais em Química como contribuição na formação continuada de professores de Química. In: XV ENCONTRO NACIONAL DE ENSINO DE QUÍMICA (XV ENEQ), Brasília, DF, Brasil. Anais eletrônicos... 2010. Disponível em: 〈http://www.xveneq2oro.unb.br/resumos/Ro750-2.pdf〉 Acesso em 22 jun. 2016.

PREFEITURA MUNICIPAL. Itaipulândia, Paraná. Disponível em: $\langle$ http://www.itaipulandia.pr.gov.br/conheca/dados-da-cidade〉 Acesso em: 2I jun. 2016.

SANTOS, G. L. L.; Laboratório Virtual: Um recurso inovador no auxílio ao ensino de química. Monografia de Conclusão de Curso (Graduação) - Licenciatura Plena em Química, Centro de Ciências e Tecnologia, Universidade Federal da Paraíba, Campina Grande, Paraíba, Brasil, 2oIr.

SILVA, R. R. et al. Experimentar sem medo de errar. In: SANTOS, W. L. P.; MALDANER, O. A. Ensino de química em foco. Ijuí: Unijuí, 2010, p. 231-26I.

SILVA, A. M.; SILVA, T. R. M. O ensino da química na visão dos alunos do ensino médio. In: 48 CONGRESSO BRASILEIRO DE QUÍMICA, Rio de Janeiro, 2008. Disponível em: 〈http://www.abq.org.br/cbq/2008/trabalhos/6/6-523-4433.htm〉 Acesso em: 29 jun. 2016.

TORETTI, Gustavo A.; ROSSI, Adriana V. Bons resultados são possíveis no difícil contexto: Ensino de Química, Informática e Escola Pública. Campinas 2003. Disponível em: 〈http://www.sbq.org.br/ranteriores/23/resumos/o39o-2/〉. Acesso em: 30 jun. 2016.

TORRICELLI, Eneas. Dificuldades de aprendizagem no Ensino de Química. 2007. (Tese de livre docência), Belo Horizonte, Universidade Federal de Minas Gerais. Faculdade de Educação, 2007.

TREVISAN, Tatiana S.; MARTINS, Pura Lúcia O. A prática pedagógica do professor de química: possibilidades e limites. UNIrevista, v. I, n. 2 : abril, 2006.

VIEIRA, Eloisa; MEIRELLES, Rosane M. S.; RODRIGUES, Denise C. G. A. O uso de tecnologias no ensino de química: a experiência do laboratório virtual química fácil. In: 
VIII ENCONTRO NACIONAL DE PESQUISA EM EDUCAÇÃO, I CONGRESO IBEROAMERICANO DE INVESTIGACIÓN EM ENSEÑANZA DE LAS CIÉNCIAS, 2oII, Campinas: Anais o VIII ENPEC - Encontro Nacional de Pesquisa em Educação em Ciências, 20II.

VYGOTSKY, L.S. A formação social da mente. São Paulo: Martins Fontes, 1989. 